\title{
Bioactivity and action mechanism of green propolis against Pythium aphanidermatum
}

\author{
WALLANCE M. PAZIN ${ }^{1,2}$, SUIKINAI N. DOS SANTOS ${ }^{3}$, SONIA C.N. QUEIROZ ${ }^{3}$, LUIS A. \\ BAGATOLLI $^{4}$, ADEMILSON E.E. SOARES ${ }^{5}$, ITAMAR S. DE MELO ${ }^{3}$ and AMANDO S. ITO ${ }^{1}$ \\ ${ }^{1}$ Departamento de Física, Faculdade de Filosofia, Ciências e Letras de Ribeirão Preto, Universidade \\ de São Paulo, Av. Bandeirantes, 3900, 14040-901 Ribeirão Preto, SP, Brazil \\ ${ }^{2}$ Departamento de Física, Faculdade de Ciências e Tecnologia, Universidade Estadual Paulista, \\ Rua Roberto Simonsen, 305, 19060-900 Presidente Prudente, SP, Brazil \\ ${ }^{3}$ Laboratório de Microbiologia Ambiental, Embrapa Meio Ambiente, Rodovia SP- \\ 340, Km 127,5, 13918-110 Jaguariúna, SP, Brazil \\ ${ }^{4}$ Instituto de Investigaciones Medicas Mercedes y Martín Ferreyra/INIMEC-CONICET-UNC, Friuli, 2434, Córdoba, Argentina \\ ${ }^{5}$ Departamento de Genética, Faculdade de Medicina de Ribeirão Preto, Universidade de \\ São Paulo, Av. Bandeirantes, 3900, 14049-900 Ribeirão Preto, SP, Brazil \\ Manuscript received on June 13, 2018; accepted for publication on August 27, 2018
}

\begin{abstract}
How to cite: PAZIN WM, SANTOS SN, QUEIROZ SCN, BAGATOLLI LA, SOARES AEE, MELO IS AND ITO AS. 2019. Bioactivity and action mechanism of green propolis against Pythium aphanidermatum. An Acad Bras Cienc 91: e20180598. DOI 10.1590/0001-3765201920180598.
\end{abstract}

\begin{abstract}
We have established how natural compounds from green propolis collected by the species Apis mellifera act against the growth of Pythium aphanidermatum. On the basis of mass spectrometry (Q-ToF MS), we determined that Artepillin C, the major constituent of green propolis, underlies the effect and displays activity against $P$. aphanidermatum at a minimal inhibitory concentration of $750 \mu \mathrm{g} \cdot \mathrm{mL}^{-1}$. Biophysical studies based on model membranes showed that this inhibitory effect may be linked with a membrane-related phenomenon: Artepillin $\mathrm{C}$ increases the permeability of membranes with relatively high fluidity in their lateral structure, a feature that is in line with the lipid composition reported for the cytoplasmic membrane of $P$. aphanidermatum. Therefore, the present study supports the use of the effective and inexpensive green propolis to control the impact of the dangerous phytopathogen P. aphanidermatum on agriculture.
\end{abstract}

Key words: green propolis, Artepillin C, fungicide, Pythium aphanidermatum, model membranes.

\section{INTRODUCTION}

Brazilian food security and environmental sustainability are globally important. Brazil is one of the three largest world producers and exporters of sugar, coffee, orange juice, soybean, beef, tobacco, ethanol, and broiler chicken. This country

Correspondence to: Wallance Moreira Pazin

E-mail: wallancepazin@gmail.com

ORCid: https://orcid.org/0000-0002-2157-5933 has one of the greatest biodiversity reserves in the globe as well as several farmers with strong entrepreneurial capability (Pereira et al. 2012, The Economist 2012). According to the latest report by the Brazilian Association of Collective Health (ABRASCO) (Carneiro et al. 2015), economic growth has encouraged the use of pesticides to expand cultivated land. Between 2000 and 2012, this practice has increased by more than 162 percent in Brazil. About $16 \%$ of the pesticides employed 
in the Brazilian agriculture consist of fungicides, which pose many problems related to antimicrobial resistance (Dasgupta et al. 2001, Price et al. 2015). Furthermore, overexposure of the population to the synthetic chemicals present in pesticides affects the human health negatively - such chemicals are toxic and highly persistent in the environment, and they can enter the food chain (Kaur and Garg 2014).

In an attempt to diminish the environmental impact of currently available fungicides, many researchers have been searching for naturally occurring bioactive compounds that act differently from commonly known antifungals. Propolis is a resinous product consisting of compounds that bees collect from the vegetation; e.g. phenolic acids, terpenoids, caffeic acids, and flavonoids (Carvalho et al. 2011, Franchin et al. 2018). These compounds are processed by the salivary enzymes of the bees, to protect their colonies against the attack of pathogens (Bonvehí and Gutiérrez 2012, Carneiro et al. 2015, Mirzoeva et al. 1997). Depending on the region where the bees collect the propolis constituents, they might display different repertory of biological actions. For instance, it is believed that terpene-rich propolis comes from Araucaria species, since several terpene derivatives are found in their resins, acting in a defense response against bark beetles, fungi, bark wound sealing, disruption of insect development and attraction of herbivore predators (Bankova et al. 1998, Perotti and FettNeto 2015).

Among all the types of Brazilian propolis, the propolis produced by the species Apis mellifera, known as green propolis and collected from Baccharis dracunculifolia plant exudates, is one of the most studied worldwide. This propolis has many pharmacological properties, such as antibacterial, antifungal, and antioxidant actions (Bastos et al. 2008, Lotfy 2006, Pazin et al. 2017, Sawaya et al. 2009). However, the agricultural benefits of green propolis remain to be explored. Studies have shown that phytochemical compounds like the ones found in green propolis can interact with and modify the structure of the biomembranes of target cells, leading membrane proteins to lose their functions and reflecting a large repertoire of biological effects (Rempe et al. 2017).

Oomycetes comprise several genera that contain important plant pathogens. For example, Pythium spp. includes a group of pathogens that damage crops to a large extent, leading to loss of millions of dollars (Rai et al. 2018, van West and Gow 2003). Pythium aphanidermatum is an aggressive false-fungal species that is highly resistant to fungicides and which causes pre- and post-emergence damping off in vegetable crops such as potato, tomato, beet, cucumber, and pepper (Garibaldi et al. 2013, Owen-Going et al. 2003, Postma et al. 2013, 2000, Sabbagh et al. 2018, Strange and Scott 2005). Rapid germination of sporangia followed by immediate infection makes management of Oomycetes very difficult (Nelson 1987, Osburn et al. 1989, van West et al. 2003, Whipps and Lumsden 1991). Vegetables and field crops affected by Pythium diseases are considered an important limiting factor to the successful cultivation of crop plants worldwide.

The full potential of the biological control of Oomycete pathogens has not been explored yet. Oomycetes differ from fungi in various aspects, including the absence of ergosterol in the lipid composition of the cytoplasmic membrane. This feature makes the application of some fungicides to combat Oomycetes useless: most fungicides, like the azole family of antifungals, act by interacting with or inhibiting ergosterol (Cheng et al. 2004).

In this study, we report observation of the deleterious effect of green propolis against $P$. aphanidermatum. We have identified the major constituent of this natural product, Artepillin C, and we have drawn conclusions on the action mechanism of this bioactive compound. We have analyzed how Artepillin $\mathrm{C}$ interacts with model membranes that mimic fungal and Oomycite cytoplasmic 
membranes. To the best of our knowledge, this is the first report that has suggested the potential use of green propolis as an anti-phytopathogen compound against $P$. aphanidermatum.

\section{MATERIALS AND METHODS}

\section{SOURCE AND COLLECTION}

Green propolis was collected from colonies of Apis mellifera honeybees (March, 2012) located in Bambuí (20¹'0"'S, 4558'0"'W - Minas Gerais State, Brazil). The ethanolic extract of propolis (EEP) was obtained by adding $300 \mathrm{~g}$ of crude propolis (compound + beeswax) extracted from the colonies to $1000 \mathrm{~mL}$ of ethyl alcohol (70\%), which was followed by maceration in the dark for two months. After this period, the extract was filtered through Whatman filter paper, to give a hydroalcoholic solution. Next, $40 \mathrm{~mL}$ aliquots of this solution were collected and placed in $50 \mathrm{~mL}$ widemouth flasks. The open flasks were transferred to an oven to eliminate the alcohol. After stabilization of the resin mass, the flasks were sealed and kept at $-20{ }^{\circ} \mathrm{C}$ for further use.

\section{BIOGUIDED FRACTIONATION}

Initially, $1.0 \mathrm{~g}$ of EEP was dissolved in methanol/ water $(90: 10, \mathrm{v} / \mathrm{v})$ and subjected to liquid/liquid partitioning with $150 \mathrm{~mL}$ of hexane (three times), to afford $165.95 \mathrm{mg}$ of hexane extracts. Then, 57 $\mathrm{mL}$ of water was added to the remaining partition (methanol/water, 90:10, v/v), to make it 70:30 (v/v) methanol/water. Next, the latter solution was partitioned with $150 \mathrm{~mL}$ of chloroform (three times), to yield $762.36 \mathrm{mg}$ of chloroform extracts. The remaining methanol was removed by rotary evaporation, which was followed by addition of $100 \mathrm{~mL}$ of ethyl acetate, to afford $66.27 \mathrm{mg}$ of ethyl acetate extracts. The water in the extract was eliminated by rotary evaporation, to give $5.42 \mathrm{mg}$ of extracts. The chloroform extracts were separated on a $30 \mathrm{~cm}$ x $5 \mathrm{~cm}$ Silica gel (Merck) column and eluted at $1 \mathrm{~mL} / \mathrm{min}$ by using solvents of increasing polarity (hexane; hexane/dichloromethane [50:50 and 25:75]; dichloromethane; dichloromethane/ methanol [75:25; 70:30; 60:40; 50:50]). The fractions were monitored by thin layer chromatography (TLC) on 10 x $10 \mathrm{~cm}$ Alugram silica gel plates (Macherey-Nagel) developed with dichloromethane/hexane/methanol (65:30:5, $\mathrm{v} / \mathrm{v} / \mathrm{v})$. After the plates were developed and dried, they were visualized under UV light at 254 and $365 \mathrm{~nm}$, and then similar fractions (10 mL each) were combined, to afford eight major fractions. The mass yield of each fraction was determined, and their biological activities (at concentrations of 5 mg. $\mathrm{L}^{-1}$ ) were tested against the phytopathogen $P$. aphanidermatum.

\section{BIOLOGICAL ACTIVITY}

The EEP was assayed against the phytopathogen $P$. aphanidermatum. The tested microorganism was obtained from the EMBRAPA Culture Collection of Microorganisms of Agricultural and Environmental Importance. The antimicrobial activity of EEP was evaluated by the agar cup disc diffusion method (Bauer et al. 1966). To this end, $5 \mathrm{mg} \cdot \mathrm{mL}^{-1}$ EEP and its bioactive fractions were tested against $P$. aphanidermatum until the bioactive compound was found. After that, the bioactive compound was tested against the microorganism at concentrations ranging from 50 to $10 \mathrm{mg} \cdot \mathrm{mL}^{-1}$. More specifically, each disc containing a total volume of $10 \mu \mathrm{L}$ of the active compound solution diluted in methanol was incubated at $28^{\circ} \mathrm{C}$ for four different times $(17,20$, 24 , and $30 \mathrm{~h}$ ). The minimal inhibitory concentration was defined as the lowest concentration of the compound that maintained inhibition of microorganism growth at $30 \mathrm{~h}$. Culture medium grown without the addition of the tested substance served as negative control. The experiments were performed in triplicate. 
Q-ToF MS ANALYSIS OF THE PROPOLIS FRACTION SAMPLES

Samples containing the propolis fractions were directly infused into a hybrid quadrupole orthogonal time of flight (Q-ToF) mass spectrometer, Synapt, Waters. Electrospray Ionization (ESI) in the negative mode was used as the ionizing source, and the software used for acquisition control and data treatment was MassLynx, version 4.1 (Waters). The capillary and cone voltages were set to 3,000 and $20 \mathrm{~V}$, respectively. The nebulization gas was maintained at a flow rate of $500 \mathrm{~L} \cdot \mathrm{h}^{-1}$ and at a temperature of $450^{\circ} \mathrm{C}$. The cone gas was maintained at a flow rate of $20 \mathrm{~L} \cdot \mathrm{h}^{-1}$, and the source temperature was set to $105{ }^{\circ} \mathrm{C}$. MS data were collected for $\mathrm{m} / \mathrm{z}$ values ranging from 70 to $1,000 \mathrm{Da}$. The scan time was $0.5 \mathrm{~s}$, and the inter-scan delay was $0.02 \mathrm{~s}$ over an analysis time of $13 \mathrm{~min}$. The $[\mathrm{M}-\mathrm{H}]^{-}$ion of the Artepillin C standard arose at $\mathrm{m} / z$ [299.1646] for the syringe pump operating at $5 \mu \mathrm{L} \cdot \mathrm{min}^{-1}$. All the MS data were collected with the LockSpray system to ensure mass accuracy and reproducibility.

\section{VESICLE PREPARATION AND CONFOCAL FLUORESCENCE MICROSCOPY}

Giant Unilamellar Vesicles (GUVs), used as model membranes, were prepared by the electroformation method developed by Angelova and Dimitrov (Angelova and Dimitrov 1986). A homemade temperature-controlled chamber was used as described previously (Husen et al. 2012). Briefly, 4 $\mu \mathrm{L}$ of the desired lipid stock solution $\left(0.2 \mathrm{mg} \cdot \mathrm{mL}^{-1}\right)$ in chloroform was spread on each platinum electrode. The chamber was then placed under vacuum for at least $1 \mathrm{~h}$, to remove any remaining trace of organic solvent. To perform leakage studies, fluorescent dyes were incorporated into the lumen of the GUVs according to Ambroggio et al. $2005 \mathrm{a}, \mathrm{b}$. For this purpose, solutions of sucrose/ AlexaFluor-488 $10 \mu \mathrm{M}$ with an overall osmolarity of $200 \mathrm{mOsM}$ were equilibrated to temperatures above the lipid phase transition and added to the chamber covering the platinum electrodes $(0.4 \mathrm{~mL}$ final volume). The platinum wires were connected to a function generator (Digimess FG 100) after addition of the buffer, and a low-frequency alternating field (sinusoidal wave function with a frequency of $10 \mathrm{~Hz}$ and amplitude of $1 \mathrm{~V}$ ) was applied for $120 \mathrm{~min}$. The AC field was turned off, and the GUVs were harvested from the chamber. To remove the fluorescent solution from outside the vesicles, the GUVs were washed several times with an iso-osmolar solution consisting of glucose in $15-\mathrm{mL}$ centrifuge tubes. Aliquots of GUVs suspended in glucose $(0.3 \mathrm{~mL})$ were added to an eight-well plastic chamber (Ibidi, Munich, Germany). Due to the different densities of the sugar solutions inside and outside the vesicles, the GUVs precipitated at the bottom of the chamber, which facilitated observation in the inverted confocal microscope (Ambroggio et al. 2005a, b). The chamber had been placed in an inverted confocal microscope (Zeiss LSM 510 META, Jena, Germany) for observation. The excitation wavelength was $488 \mathrm{~nm}$ for AlexaFluor-488. Either Artepillin $\mathrm{C}$ methanol solution or pure methanol $1 \%(\mathrm{v} / \mathrm{v})$ was injected into the chamber, and a timeseries scan was initiated to monitor the GUVs. The experiments were performed in triplicate. After the injections, several vesicles were monitored as a function of time in each experiment. All the leakage experiments were analyzed by taking the change in fluorescence intensity as the average gray value measured for each micrograph of AlexaFluor-488 inside the GUVs. The ImageJ software was used for this measurement. The negative control comprised samples without Artepillin C.

\section{RESULTS}

\section{BIOLOGICAL ACTIVITY OF PROPOLIS}

COMPOUNDS AGAINST P. aphanidermatum

First, we investigated whether the ethanolic extract of propolis (EEP) inhibited the phytopathogen $P$. aphanidermatum and verified good activity. We then used a bioassay-directed fractionation to separate the EEP molecules that were bioactive 
against the phytopathogen. Compounds separated in chloroform were the most active against $P$. aphanidermatum. The flowchart in Figure 1 illustrates the bioguided assay processes.

The chloroform fraction, which was the most active against the target phytopathogen, was further separated on a chromatographic column, to afford eight subfractions. These subfractions were also assayed against $P$. aphanidermatum. Q-ToF MS indicated the presence of a major compound [M-H], $m / z$ 299.1641, in the bioactive fraction, identified as Artepillin C.

Artepillin $\mathrm{C}$ at concentrations ranging from $50 \mu \mathrm{g} . \mathrm{mL}^{-1}$ to $1 \mathrm{mg} \cdot \mathrm{mL}^{-1}$ was tested against $P$. aphanidermatum. Solutions of the compound were placed into agar cup discs containing the phytopathogen. Analysis performed after 17 hours indicated resistance to $P$. aphanidermatum diffusion near the region between 50 and $125 \mu \mathrm{g} \cdot \mathrm{mL}^{-1}$. Three hours later, only regions with concentrations higher than $250 \mu \mathrm{g} \mathrm{mL}^{-1}$ were able to restrain the growth of $P$. aphanidermatum. This activity persisted for up to 24 hours for the concentrations 250 and 500 $\mu \mathrm{g} . \mathrm{mL}^{-1}$ and for up to 30 hours for concentrations above $750 \mu \mathrm{g} . \mathrm{mL}^{-1}$, defined as the minimum inhibitory concentration (Figure 2).

\section{INTERACTION OF ARTEPILLIN C WITH MODEL MEMBRANES}

Confocal fluorescence microscopy was used to investigate permeability changes in model membranes. We are aware that DOPC-GUVs have a simple composition, but they offer a plausible model that represents the major class of lipid species present in an Oomycite cytoplasmic membrane; i.e., DOPC-GUVs contain high levels of unsaturated lipids but no sterols. We have also tested another GUV composition containing sterols in an attempt to mimic fungal membranes. More specifically, we used a mixture of DOPC, DPPC, and cholesterol at a molar ratio of 23:47:30. In this latter model, liquid ordered and liquid disordered

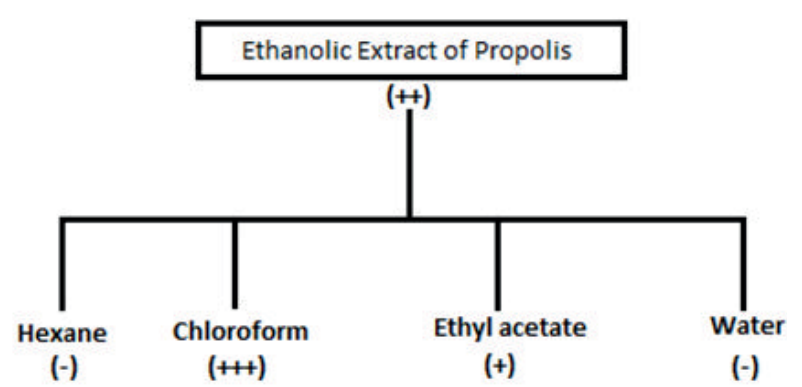

Figure 1 - Representative flowchart of the fractionation process of the ethanolic extract of propolis (EEP) with solvents of different polarities and activities of the fractions against $P$. aphanidermatum. (-) no activity; (+) weak activity; (++) good activity; and $(+++)$ high activity against $P$. aphanidermatum.

phases coexist at room temperature (Husen et al. 2012), which implies a substantial increase in the membrane order parameter (or a decrease in the overall membrane fluidity). Figure 3 shows that addition of Artepillin $\mathrm{C}$ diminished the initial fluorescence intensity observed in the lumen of the DOPC- GUVs over time. This indicated that the dye leaked from the DOPC-GUVs to the outer solution, as previously observed in the case of antibiotic peptides (Ambroggio et al. 2005a, b). Hence, Artepillin C enhanced the permeability of the bilayer. Similar experiments performed with the GUVs consisting of DOPC/DPPC/Cholesterol (23:47:30 $\mathrm{mol} / \mathrm{mol})$ clearly showed that Artepillin $\mathrm{C}$ did not affect the permeability of the latter vesicles at all (Figure 3a, b).

\section{DISCUSSION}

The propolis produced by the species Apis mellifera, known as green propolis and collected from Baccharis dracunculifolia plant exudates has many pharmacological properties, such as antibacterial, antifungal, and antioxidant actions. Therefore, it is a potent natural product for the biological control of phytopathogens in agriculture. We observed that the ethanolic extract of propolis (EEP) presented activity against the phytopathogen $P$. aphanidermatum and a bioassay-directed fractionation on the EEP showed that compounds 


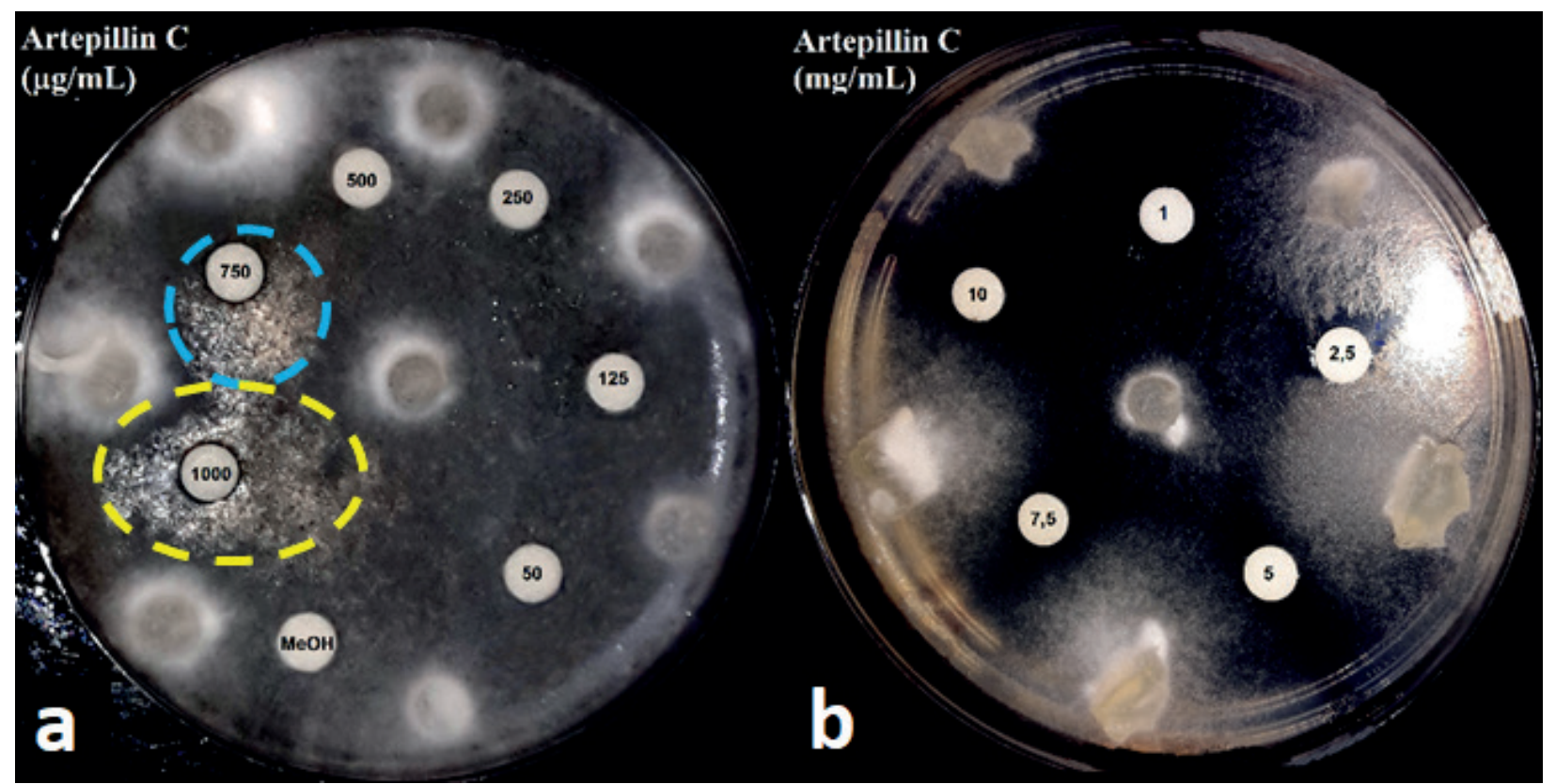

Figure 2 - Analysis of $P$. aphanidermatum growth in agar cup discs after 30 hours in the presence of Artepillin C. a) Artepillin $\mathrm{C}$ concentrations ranging from 50 to $1000 \mu \mathrm{g} \cdot \mathrm{mL}^{-1}$ and methanol $(\mathrm{MeOH})$ as negative control (blue and yellow dashed circles represent the inhibition zone for 750 and $1000 \mu \mathrm{g} \cdot \mathrm{mL}^{-1}$, respectively); b) Artepillin C concentrations ranging from 1 to $10 \mathrm{mg} \cdot \mathrm{mL}^{-1}$.
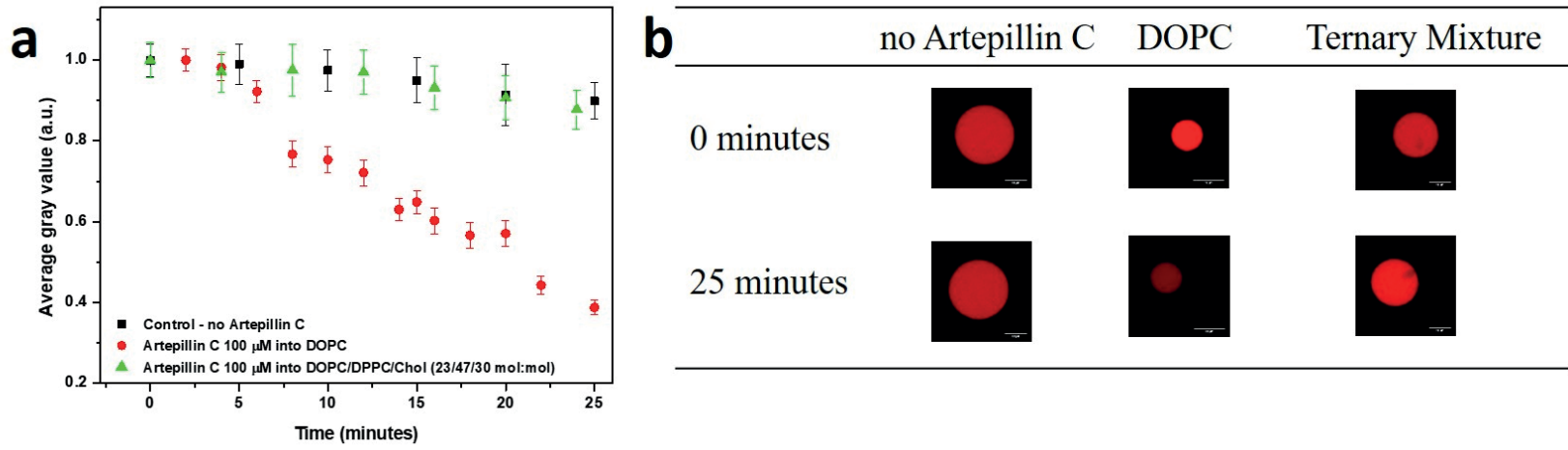

Figure 3 - a) AlexaFluor-488 release kinetics from inside the GUV membrane models after insertion of Artepillin C, as evaluated by confocal fluorescence microscopy. Black squares: control - no Artepillin C; red dots: $100 \mu \mathrm{M}$ of Artepillin C into fluid-phase GUV formed of DOPC; green triangles: $100 \mu \mathrm{M}$ Artepillin C into liquid-ordered/liquid-disordered GUVs consisting of a ternary mixture of DOPC/DPPC/cholesterol (23/47/30 mol:mol:mol). b) Representative images of DOPC-GUVs and GUVs consisting of a ternary mixture of DOPC/DPPC/cholesterol (23/47/30 mol:mol:mol) at the initial ( 0 minutes) and final (25 minutes) fluorescence intensity analyses.

separated in chloroform were the most active against $P$. aphanidermatum. The chloroform fraction was separated on a chromatographic column, and Q-ToF MS identified Artepillin C as a major compound in the bioactive fraction. The tests of Artepillin $\mathrm{C}$ against $P$. aphanidermatum demonstrated resistance to $P$. aphanidermatum diffusion depending on the concentration of the compound. The activity persisted for 30 hours at concentrations above $750 \mu \mathrm{g} \cdot \mathrm{mL}^{-1}$, defined as the minimum inhibitory concentration.

Green propolis displays a large spectrum of pharmacological properties and, particularly, it is one of the most famous propolis in the world due to the high amount of cinnamic acid in its composition, especially Artepillin C. This compound has 
molecular formula $\mathrm{C}_{19} \mathrm{H}_{24} \mathrm{O}_{3}$, low molecular weight (300.39 g.mol ${ }^{-1}$ ), and bears two prenylated groups bound to a phenyl group (Figure 4).

Artepillin $\mathrm{C}$, identified as the major compound of green propolis, underlies many biological effects against pathogens of different species; moreover, it displays antioxidant, anti-inflammatory, and antitumor activities (Kimoto et al. 1998, Paulino et al. 2008, Shimizu et al. 2004). To the best of our knowledge, no research has tested Artepillin C or green propolis as potential anti-phytopathogen compounds. A previous study has shown that the structure of Artepillin C favors its interaction with amphiphilic aggregates such as cell membranes. This interaction is mainly favored by the presence of two prenylated bonds in Artepillin C, which enhance the hydrophobicity of this bioactive compound (Pazin et al. 2017). It is important to notice that the hydrophobic effects of Artepillin $\mathrm{C}$ depends on the protonation state of its carboxyl group, which could improve its partition to the lipid environment (Camuri et al. 2018). Such affinity allows the compound to modify the structure of the biomembranes of target cells, possibly affecting membrane proteins function and inducing a large repertoire of biological effects. Here, it is worth noting that the membrane of $P$. aphanidermatum consists of saturated and mainly of unsaturated lipids; sterols are absent (Avis and Belanger 2001) and, interestingly, leakage effects was observed only for the model that contains the major class of lipid species present in the $P$. aphanidermatum membrane. The different effects observed for the two tested GUV compositions could be related to the structure of the membranes, which in turn influenced the partition of the active compound to the membrane: a pure liquid disordered phase should favor partition of the active compound compared to a more rigid membrane, enhancing the effect of the target compound on the permeability of the membrane.

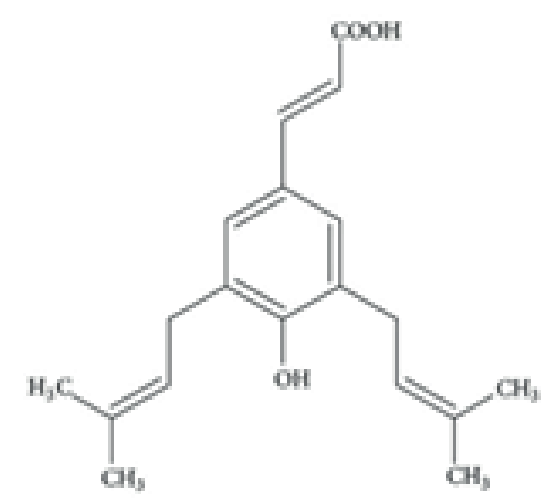

Figure 4 - Molecular structure of Artepillin C.

Avis and Bélanger (2001) have investigated how the antifungal fatty acid cis-9-heptadecenoic acid acts against different fungal groups. In contrast to some specific antifungal compounds that interact with membrane sterols, cis-9-heptadecenoic acid specifically acted on $P$. aphanidermatum, which contains little or no sterol and has unsaturated lipids in the cytoplasmic membrane. The authors concluded that the high content of unsaturated lipids in the membrane of $P$. aphanidermatum enhanced the deleterious effect of cis-9-heptadecenoic acid, which promoted higher bilayer fluidity and increased the permeability of the membrane. Remarkably, our findings pointed to a similar action mechanism for Artepillin C: the presence of unsaturated lipids and the absence of sterol in DOPC-GUVs enhanced the effect of Artepillin C on the membrane - membrane permeability changed and probably caused release of intracellular materials and cytoplasmic disintegration of mycelia and spores.

Strategies to combat phytopathogen species belonging to the Oomycete Class have not received much attention, and few studies have been conducted in this field. Our results herein indicate that green propolis might be an advantageous ecological alternative for the biological control of pythiaceous species. The obtained data suggest that green propolis is an effective and inexpensive alternative to control the dangerous phytopathogen 
P. aphanidermatum by small farming communities and in large plantations.

\section{ACKNOWLEDGMENTS}

We thank the Brazilian agencies Coordenação de Aperfeiçoamento de Pessoal de Nível Superior (CAPES - process number 004137/2014-00) and Conselho Nacional de Desenvolvimento Científico e Tecnológico (CNPq) for fellowships, and Dr. Marcia Regina Assalin and M.Sc. Rodrigo Castanha for help with the Q-Tof MS equipment and bioassay, respectively. We also thank Cynthia Maria de Campos Prado Manso for helping to revise the English language. WMP thanks Fundação de Amparo à Pesquisa do Estado de São Paulo (FAPESP - process number 2016/09633-4) for his post-doctoral fellowship. ASI is a recipient of a CNPq research grant (305771/2016-7). The authors acknowledge the Danish Molecular Biomedical Imaging Center (DaMBIC, University of Southern Denmark) for the use of the bioimaging facilities.

\section{AUTHOR CONTRIBUTIONS}

WMP - Conceptualization, Methodology, Data curation and Writing; SNS, SCNQ and LAB Methodology, Data curation and Writing; AEES and ISM - Resources, Funding Acquisition; ASI - Conceptualization, Methodology, Data curation, Writing and Supervision.

\section{REFERENCES}

AMBRoggio EE, KIM DH, SEPAROVIC F, BARROW CJ, BARNHAM KJ, BAGATOLLI LA AND FIDELIO GD. 2005a. Surface Behavior and Lipid Interaction of Alzheimer Beta-Amyloid Peptide 1-42: A Membrane-Disrupting Peptide. Biophys J 88(4): 2706-2713.

AMBROGGIO EE, SEPAROVIC F, BOWIE JH, FIDELIO GD AND BAGATOLLI LA. 2005b. Direct Visualization of Membrane Leakage Induced by the Antibiotic Peptides: Maculatin, Citropin, and Aurein. Biophys J 89(3): 18741881.
ANGELOVA MI AND DIMITROV DS. 1986. Liposome Electroformation. Faraday Discuss 81: 303.

AVIS TJ AND BELANGER RR. 2001. Specificity and Mode of Action of the Antifungal Fatty Acid Cis-9Heptadecenoic Acid Produced by Pseudozyma Flocculosa. Appl Environ Microbiol 67(2): 956-960.

BANKOVA V, BOUDOUROVA-KRASTEVA G, POPOV S, SFORCIN JM AND FUNARI SRC. 1998. Seasonal Variations of the Chemical Composition of Brazilian Propolis. Apidologie 29(4): 361-367.

BASTOS EMAF, SIMONE M, JORGE DM, SOARES AEE AND SPIVAK M. 2008. In vitro Study of the Antimicrobial Activity of Brazilian Propolis against Paenibacillus Larvae. J Invertebr Pathol 97(3): 273-281.

BAUER AW, KIRBY WM, SHERRIS JC AND TURCK M. 1966. Antibiotic Susceptibility Testing by a Standardized Single Disk Method. Am J Clin Pathol 45(4): 493-496.

BONVEHÍ JS AND GUTIÉRREZ AL. 2012. The Antimicrobial Effects of Propolis Collected in Different Regions in the Basque Country (Northern Spain). World J Microbiol Biotechnol 28(4): 1351-1358.

CAMURI IJ, COSTA AB, ITO AS AND PAZIN WM. 2018. Optical Absorption and Fluorescence Spectroscopy Studies of Artepillin C, the Major Component of Green Propolis. Spectrochim Acta A 198: 71-77.

CARNEIRO FF, RIGOTTO RM, AUGUSTO LGS, FRIEDRICH K AND BÚRIGO AC. 2015. Dossiê ABRASCO - Um Alerta Sobre Os Impactos Dos Agrotóxicos Na Saúde.

CARVALHO AA ET AL. 2011. In vivo Antitumoural Activity and Composition of an Oil Extract of Brazilian Propolis. Food Chem 126(3): 1239-1245.

CHENG CS, SAMUEL D, LIW YJ, SHYU JC, LAI SM, LIN KF AND LYU PC. 2004. Binding Mechanism of Nonspecific Lipid Transfer Proteins and Their Role in Plant Defense. Biochemistry 43(43): 13628-13636.

DASGUPTA SNM AND MEISNER C. 2001. Pesticide Use in Brazil in the Era of Agroindustrialization and Globalization. Environ Dev Econ 6: 459-482.

FRANCHIN M， FREIRES IA， LAZARINI JG, NANI BD, CUNHA MG, COLÓN DF, ALENCAR SM AND ROSALEN PL. 2018. The Use of Brazilian Propolis for Discovery and Development of Novel Anti-Inflammatory Drugs. Eur J Med Chem 153: 49-55.

GARIBALDI A, GILARDI G, ORTU G AND GULLINO ML. 2013. First Report of Damping-off Caused by Pythium Aphanidermatum on Leaf Beet (Beta Vulgaris Subsp. Vulgaris) in Italy. Plant Dis 97(2): 292.

HUSEN P, ARRIAGA LR, MONROY F, IPSEN JH AND BAGATOLLI LA. 2012. Morphometric Image Analysis of Giant Vesicles: A New Tool for Quantitative 
Thermodynamics Studies of Phase Separation in Lipid Membranes. Biophys J 103(11): 2304-2310.

KAUR H AND GARG H. 2014. Pesticides: Environmental Impacts and Management Strategies. In: Larramendy ML and Soloneski S (Eds), Pesticides - Toxic Aspects. IntechOpen.

KIMOTO T, ARAI S, KOHGUCHI M, AGA M, NOMURA Y, MICALLEF MJ, KURIMOTO M AND MITO K. 1998. Apoptosis and Suppression of Tumor Growth by Artepillin C Extracted from Brazilian Propolis. Cancer Detect Prev 22(6): 506-515.

LOTFY M. 2006. Biological Activity of Bee Propolis in Health and Disease. Asian Pac J Cancer Prev 7(1): 22-31.

MIRZOEVA OK, GRISHANIN RN AND CALDER PC. 1997. Antimicrobial Action of Propolis and Some of Its Components: The Effects on Growth, Membrane Potential and Motility of Bacteria. Microbiol Res 152(3): 239-246.

NELSON EB. 1987. Rapid Germination of Sporangia of Pythium Species in Response to Volatiles from Germination Seeds. Phytopathology 77: 1108-1112.

OSBURN RM, SCHROTH MN, HANCOCK JG AND HENDSON M. 1989. Dynamics of Sugar Beet Seed Colonization by Pythium-Ultimum and Pseudomonas Species Effects on Seed Rot and Damping-Off. Phytopathology 79(6): 709-716.

OWEN-GOING N, SUTTON JC AND GRODZINSKI B. 2003. Relationships of Pythium isolates and Sweet Pepper Plants in Single-Plant Hydroponic Units. Can. J Plant Pathol 25(2): 155-167.

PAULINO N ET AL. 2008. Anti-Inflammatory Effects of a Bioavailable Compound, Artepillin C, in Brazilian Propolis. Eur J Pharmacol 587(1-3): 296-301.

PAZIN WM, MÔNACO LM, SOARES AEE, MIGUEL FG, BERRETA AA AND ITO AS. 2017. Antioxidant Activities of Three Stingless Bee Propolis and Green Propolis Types. J Apic Res 56(1): 40-49.

PEREIRA P, MARTHA GB, SANTANA CAM AND ALVES E. 2012. The Development of Brazilian Agriculture: Future Technological Challenges and Opportunities. Agriculture \& Food Security 1(1): 4.

PEROTTI JC, RODRIGUES-CORREAA KCS AND FETTNETO AG. 2015. Control of Resin Production in Araucaria Angustifolia, an Ancient South American Conifer edited by K. Leiss. Plant Biol 17(4): 852-859.

POSTMA JF, CLEMATIS EHN AND SOMEUS E. 2013. Efficacy of Four Phosphate-Mobilizing Bacteria Applied with an Animal Bone Charcoal Formulation in Controlling
Pythium Aphanidermatum and Fusarium Oxysporum f. sp. Radicis Lycopersici in Tomato. Biol Control 67(2): 284291.

POSTMA JF, WILLEMSEN-DE-KLEIN MJ AND VAN ELSAS JD. 2000. Effect of the Indigenous Microflora on the Development of Root and Crown Rot Caused by Pythium Aphanidermatum in Cucumber Grown on Rockwool. Phytopathology 90(2):125-33.

PRICE CL, PARKER JE, WARRILOW AGS, KELLY DE AND KELLY SL. 2015. Azole Fungicides - Understanding Resistance Mechanisms in Agricultural Fungal Pathogens. Pest Manag Sci 71(8): 1054-1058.

RAI M, INGLE AP, PARALIKAR P, ANASANE N, GADE R AND INGLE P. 2018. Effective Management of Soft Rot of Ginger Caused by Pythium spp. and Fusarium spp.: Emerging Role of Nanotechnology. Appl Microbiol Biotechnol 102(4): 1-13.

REMPE CS, BURRIS KP, LENAGHAN SC AND STEWART CN. 2017. The Potential of Systems Biology to Discover Antibacterial Mechanisms of Plant Phenolics. Front Microbiol 8: 422.

SABBAGH E, SABBAGH SK, PANJEHKEH N AND BOLOK-YAZDI HR. 2018. Jasmonic Acid Induced Systemic Resistance in Infected Cucumber by Pythium Aphanidermatum. J Agri Sci 24: 143-152.

SAWAYA ACHF, CALADO JCP, SANTOS LC, MARCUCCI MC, AKATSU IP, SOARES AEE, ABDELNUR PV, CUNHA IBS AND EBERLIN MN. 2009. Composition and Antioxidant Activity of Propolis from Three Species of Scaptotrigona Stingless Bees. Journal of ApiProduct and ApiMedical Science 1(2): 37-42.

SHIMIZU K, ASHIDA H, MATSUURA Y AND KANAZAWA K. 2004. Antioxidative Bioavailability of Artepillin C in Brazilian Propolis. Arch Biochem Biophys 424(2): 181188.

STRANGE RN AND SCOTT PR. 2005. Plant Disease: A Threat to Global Food Security. Annu Rev Phytopathol 43: 83-116.

THE ECONOMIST. 2012. EIU (Economist Intelligence Unit): Agriculture in High-Growth Markets: Securing Global Food Supplies.

VAN WEST P, APPIAH AAAND GOW NAR. 2003. Advances in Research on Oomycete Root Pathogens. Physiol Mol Plant Pathol 62(2): 99-113.

WHIPPS JM AND LUMSDEN RD. 1991. Biological Control of Pythium Species. Biocontrol Sci Technol 1(2): 75-90. 